\title{
Study on Seismic Performance of Continuous Rigid Frame Bridge Based on Pushover and IDA Analysis
}

\author{
Tang -Tang ${ }^{1, a^{*}}$, Yong-Jiu Qian ${ }^{1}$, Yong-Shui -Zhang ${ }^{2}$
}

${ }^{1}$ School of Civil Eng., Southwest Jiaotong University, Chengdu 610031, China; \&Sichuan Huateng road test for detection of limited liability company, Chengdu 611730, China

${ }^{2}$ School of Civil Eng., Southwest Jiaotong University, Chengdu, 610031, China

${ }^{3}$ School of Civil Engineering \& Architecture, Chongqing Jiaotong University, Chongqing, 400074, China

E-mail addresses:tangtang_scht@126.com

Keywords: Continuous rigid frame bridge; Pushover; Incremental Dynamic Analysis; performance evaluation

Abstract : Based on the restriction of Chinese seismic design criterion, which is only applied to regular bridges whose column heights are lower than $40 \mathrm{~m}$, a typical high pier and long span rigid bridge is used in this study . The typical nonlinear numerical analysis model is built for long-span continuous rigid frame bridge with high piers based on the fiber model. A special Pushover method is proposed for nonlinear analysis on the structure under the earthquake in longitudinal and transversal direction respectively. Incremental Dynamic Analysis method is performed with the nonlinear dynamic history analysis for comparison the results. At the same time, the application of the two methods in the continuous rigid frame bridge is analyzed and compared. The analysis results show that the Pushover and IDA analysis method can be used to evaluate the seismic performance of high pier continuous rigid frame bridge.

\section{Introduction}

The continuous rigid frame bridge, which has fewer piers and across large capacity and reasonable cost, has become the main form of bridge structure of the valley of the western mountains ditch. Because of the large span of continuous rigid frame bridges, the seismic response is more complex, and the seismic response of the continuous rigid frame bridge is more complex, and the seismic performance of the continuous rigid frame bridge has gradually strengthened in recent years. Specification for Guidelines for "Seismic Design of Highway Bridges (B02-01- JTG/T 2008)" mainly applied to the pier height of not more than $40 \mathrm{~m}$ of the rules of the bridge [1], so the seismic performance evaluation of long span continuous rigid frame bridge with the high pier is a hot spot of the bridge seismic research [2-8].

At present, domestic and international norms generally recommended for the seismic performance evaluation method mainly include: nonlinear static analysis (Pushover) method and incremental dynamic analysis (IDA). In this paper, the pushover and IDA analysis of a high pier and long-span continuous rigid frame bridge is carried out, which provides a theoretical basis for evaluating the seismic performance of high pier and large span structures. 


\section{Analytical model and Seismic ground motions}

\section{Analytical model}

In order to analyze the seismic performance of the bridge, the more accurate fiber element is used in this paper, and a full bridge model is established to analyze the bridge. Taking a continuous rigid frame bridge as the analysis object. The software is used for SAP2000, and the bridge pier is used in fiber unit, and the fiber is divided into Fig.1. The main girder is a beam element, the mass distribution of the bridge is built according to the actual distribution of the bridge, and the bridge model is shown in Fig. 2.

The constitutive relation of steel bar is used in the elastic plastic model. The steel bar is HRB335, the yield stress is $335 \mathrm{MPa}$, the elastic modulus is $2.0 \times 10^{5} \mathrm{MPa}$, and the ultimate strain is 0.05. Mander model is used in the concrete constitutive model. The core concrete yield force $32.4 \mathrm{MPa}$ yield strain was 0.0039 , the ultimate compressive stress of $38.56 \mathrm{MPa}$, ultimate strain of 0.035 , the calculation of the structure of the material damping using Rayleigh damping.

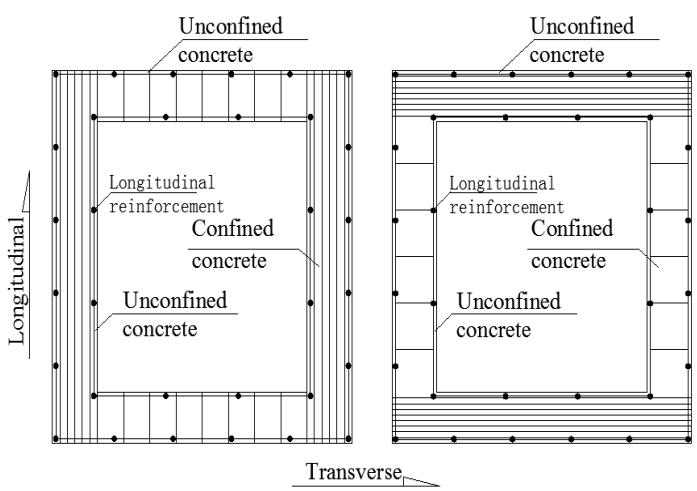

Fig. 1 .The section of the piers

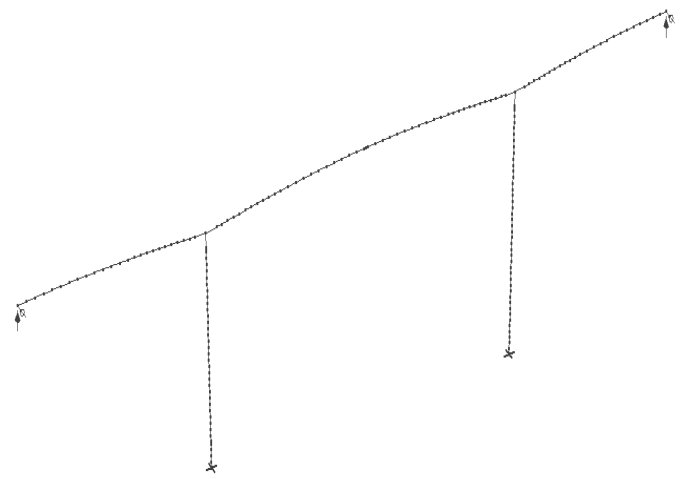

Fig. 2. Bridge model

\section{Seismic ground motions}

The process of IDA analysis has a close relationship with the characteristics of the selected seismic waves. Table 1 shows the choice of earthquake wave [9]. In IDA analysis of bridge, the maximum displacement of shear force and pier top of bridge under different seismic wave crest values are calculated by the method of PGA.

\begin{tabular}{c|c|l}
\hline $\begin{array}{c}\text { Wave } \\
\text { number }\end{array}$ & $\begin{array}{c}\text { Earthquake } \\
\text { acceleration peak /g }\end{array}$ & \multicolumn{1}{|c}{ Ground motion record } \\
\hline W1 & 0.369 & 1994, Northridge, Santa Monica \\
\hline W2 & 0.214 & 1940, El Centro Site \\
\hline W3 & 0.171 & 1985, Mexico City, Station 1 \\
\hline W4 & 0.270 & 1971, San Fernando, 159 Deg \\
\hline W5 & 0.777 & $\begin{array}{l}1979, \text { Bonds Corner El Centro, 220 } \\
\text { Deg }\end{array}$ \\
\hline W6 & 0.059 & $\begin{array}{l}1952, \text { Hollywood Storage P.E., 270 } \\
\text { Deg Acceleration/a }\end{array}$ \\
\hline
\end{tabular}

Table1 IDA analysis of ground motion records 


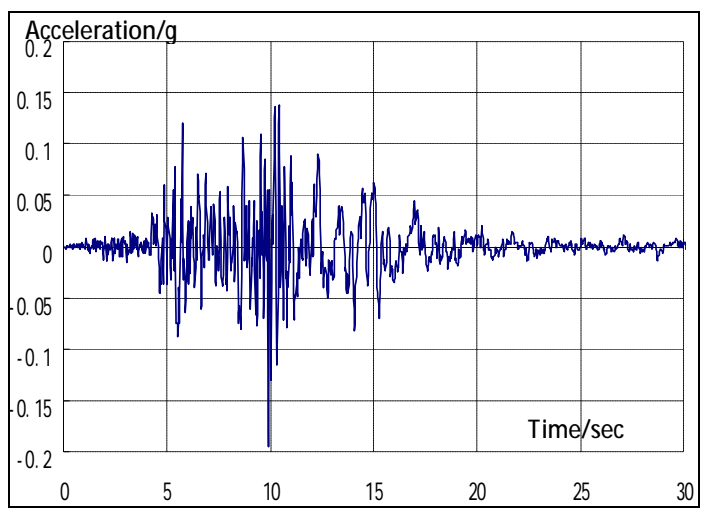

a) 1994, Northridge (w1)

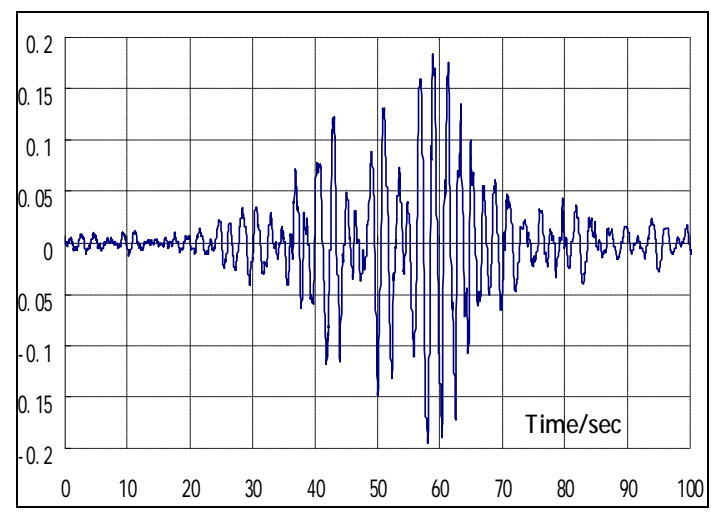

b) 1940, El Centro Site (w3)

Fig.3. Dominant waves

\section{Structural dynamic properties}

Table 2 shows the dynamic properties of the bridge and the effective modal mass of the first 5 modes. These properties include the P-Delta effect, this effect can be quite important in continuous rigid frame bridge where the structural system is essentially a compression structure. It is observed that cumulative effective mass is not enough to accurately evaluate the response of the model, so in the different analysis the firs t100 modes by means of Ritz vectors were considered, exceeding in this way the $95 \%$ of cumulative mass. The fundamental period, $2.66 \mathrm{~s}$, corresponds to the out-of-plane bending of the bridge; the second mode of translation in longitudinal direction. Fig.4 shows the mode shapes of these two modes.

\begin{tabular}{|c|c|c|c|c|c|}
\hline \multirow[b]{2}{*}{ mode } & \multirow{2}{*}{$\begin{array}{l}\text { Period } \\
(\mathrm{Sec})\end{array}$} & \multicolumn{3}{|c|}{ Mode mass } & \multirow{2}{*}{$\begin{array}{l}\text { Deflection } \\
\text { mode }\end{array}$} \\
\hline & & $\begin{array}{l}\text { Longitudinal } \\
(\%)\end{array}$ & $\begin{array}{c}\text { Transverse } \\
(\%)\end{array}$ & Vertical (\%) & \\
\hline 1 & 2.66 & 0.000 & 0.700 & 0.000 & ane \\
\hline 2 & 1.99 & 0.795 & 0.680 & 0.000 & In-plane \\
\hline 3 & 1.55 & 0.795 & 0.720 & 0.000 & ane \\
\hline 4 & 1.02 & 0.796 & 0.720 & 0.075 & $\begin{array}{ll}\text { One } & \\
\text { ane } & \\
\end{array}$ \\
\hline 5 & 0.82 & 0.848 & 0.795 & 0.368 & In-plane \\
\hline
\end{tabular}

Table 2 Natural periods and frequency 


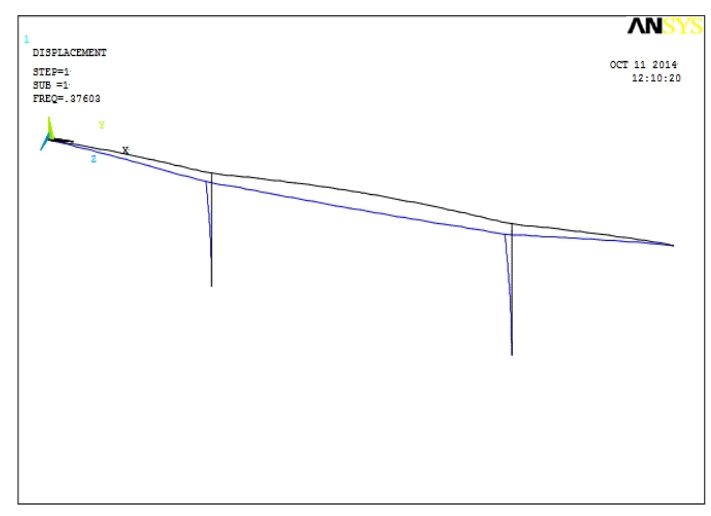

(a)mode 1

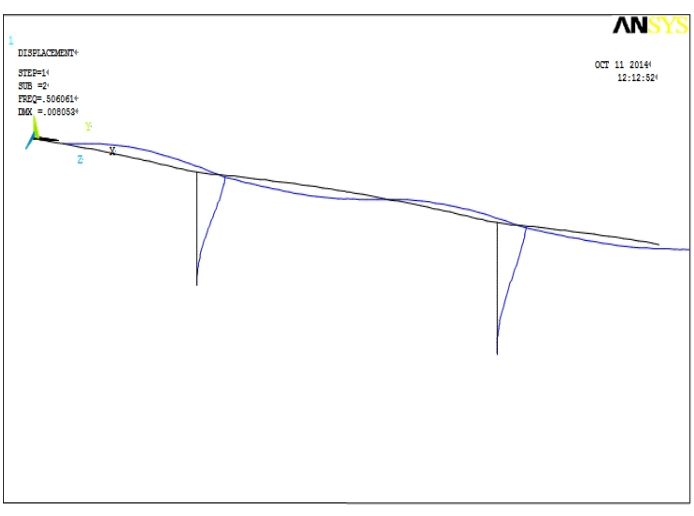

(b) mode 2

Fig.4. Modal shapes of dominant modes

\section{Seismic performance evaluation}

\section{pushover analysis results}

In the establishment of the model of the bridge, the curve of the shear force and displacement at the bottom of pier, the three kinds of lateral force distribution mode (the uniform force distribution, the first vibration mode and the SRSS) longitudinally and transversely, were used in Pushover analysis.

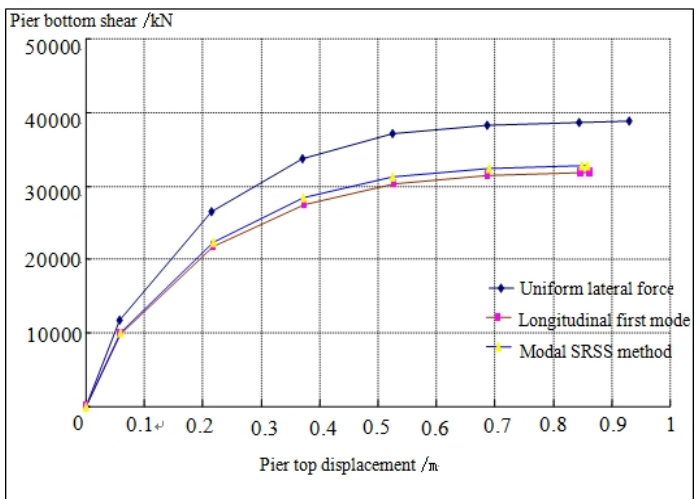

(a)longitudinally

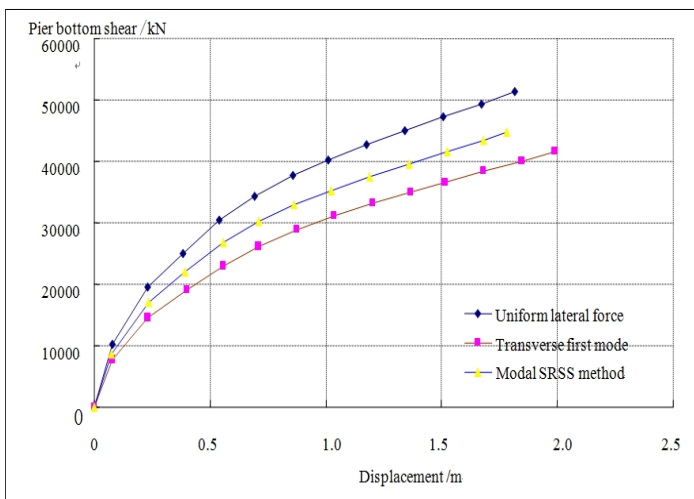

(b) transversely

Fig. 5. The curve of the shear force and displacement at the bottom of pier

Fig. 5 shows the shear force and displacement at the bottom of pier using the uniform distribution is more than that of the first order mode and the SRSS curve of the pushover method. And contrast longitudinal modal and SRSS method curve, which is due to include higher modes influence the SRSS method, can that higher mode for the bridge along the bridge to the pushover effects not so obvious. Fig. 5 displays the three lateral distribution force of the pushover curve and uniformly distributed lateral force analysis of pier bottom larger shear, and the first-order modal analysis get smaller shear. Comparison of the first-order modal method and the SRSS method analysis in transversely, the two analysis results are bigger, which means in the pier is high, the bridge seismic response of higher modes have great influence, The influence of high vibration modals should be considered for the long-span continuous rigid frame bridge with high piers in transversely 


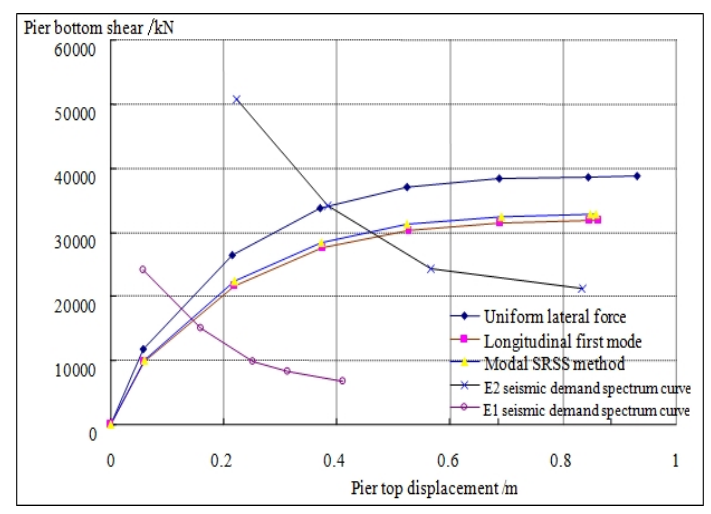

a) Longitudinal

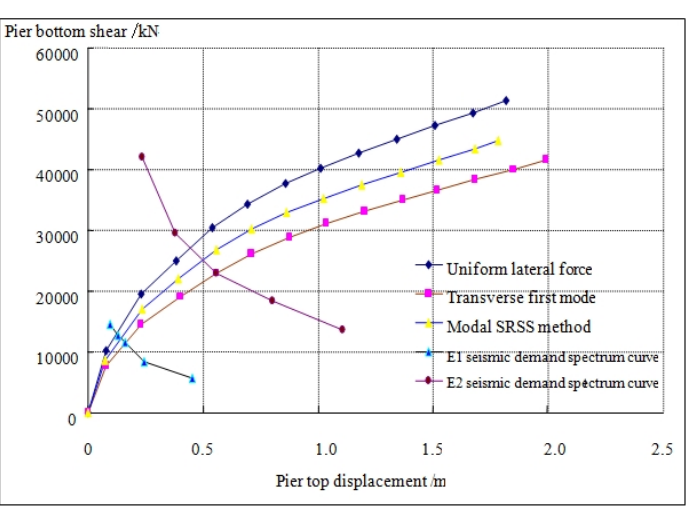

b) Transverse

Fig. 6. Seismic capacity spectrums

\begin{tabular}{|c|c|c|c|c|c|}
\hline \multirow{2}{*}{\multicolumn{2}{|c|}{ Project }} & \multicolumn{2}{|c|}{$\begin{array}{c}\text { Longitudinal performance } \\
\text { point }\end{array}$} & \multicolumn{2}{|c|}{$\begin{array}{c}\text { Transverse performance } \\
\text { point }\end{array}$} \\
\hline & & Shear $/ \mathrm{kN}$ & Displacement $/ \mathrm{m}$ & Shear $/ \mathrm{kN}$ & Displacement $/ \mathrm{m}$ \\
\hline \multirow{2}{*}{$\begin{array}{l}\text { Uniform } \\
\text { lateral force }\end{array}$} & E1 & 17750 & 0.131 & 10740 & 0.085 \\
\hline & E2 & 35010 & 0.398 & 23480 & 0.340 \\
\hline \multirow{2}{*}{$\begin{array}{c}\text { First mode } \\
\text { lateral force }\end{array}$} & E1 & 17890 & 0.175 & 11350 & 0.152 \\
\hline & $\mathrm{E} 2$ & 32210 & 0.561 & 23150 & 0.538 \\
\hline \multirow{2}{*}{$\begin{array}{l}\text { Modal SRSS } \\
\text { method }\end{array}$} & E1 & 17820 & 0.158 & 11720 & 0.125 \\
\hline & E2 & 31120 & 0.508 & 23580 & 0.420 \\
\hline
\end{tabular}

Table 3 Bridge performance point

According to the specification for Specification for Guidelines for "Seismic Design of Highway Bridges (B02-01- JTG/T 2008)", the bridge seismic performance must be needed to small earthquake (E1 earthquake) for strength checking, a large earthquake (E2 earthquake) for ductility calculation. This section for bridge ductility calculation, according to the Bridge in this paper calculated the pushover curve according to the above principles into capacity curve and the "Seismic Design of Highway Bridges (B02-01- JTG/T 2008)" in horizontal acceleration response spectrum reduction demand spectrum. Fig.6 shows the displacement of the bridge under the earthquake action of E2 is less than the yield or the limit displacement of the structure, so the bridge is not destroyed under the action of E2 earthquake.

\section{IDA analysis results}

Due to the high pier of continuous rigid frame bridge and the influence of the shear force, the displacement of the pier under the earthquake is not the same, the change of curvature can reflect the rotation and deformation of the pier structure, and the relationship between the maximum curvature and the acceleration peak value is extracted.

As can be seen from Figure 7, under different seismic waves, the maximum curvature of the pier is discrete. Under different seismic waves, even though the peak values are the same, But the seismic response of the bridge is different. With the action of W2, W3 and W6 three seismic waves, the section curvature of the longitudinal pier reached 0.001 , and the lateral curvature could reach 0.0008. And it can be seen that the maximum curvature of bridge pier increases with the increase of the peak value of seismic wave. While in the structure of the structure into the plastic, the increase of curvature becomes faster.

In order to change of curvature analysis along the pier, Fig 7 shows the curvature maximum 
curvature distribution at the bottom of pier, considering $0.1 \mathrm{~g}, 0.3 \mathrm{~g}, 0.8 \mathrm{~g}$ and $1.2 \mathrm{~g}$ of peak acceleration under in W3 wave. It can be also seen that when the bridge is subjected to the longitudinal earthquake, owing to consolidated of the bridge pier and the main girder, at the top and the bottom of the pier will have a greater curvature, which were both into the plastic state, but In the middle of the pier still was in the elastic state. While the bridge is subjected to transverse seismic action, there is a large curvature at the bottom of the pier different with the longitudinal. With the increase of the peak acceleration, Seismic response of bridge piers will also be improved, and the curvature of bridge pier will also be increased.

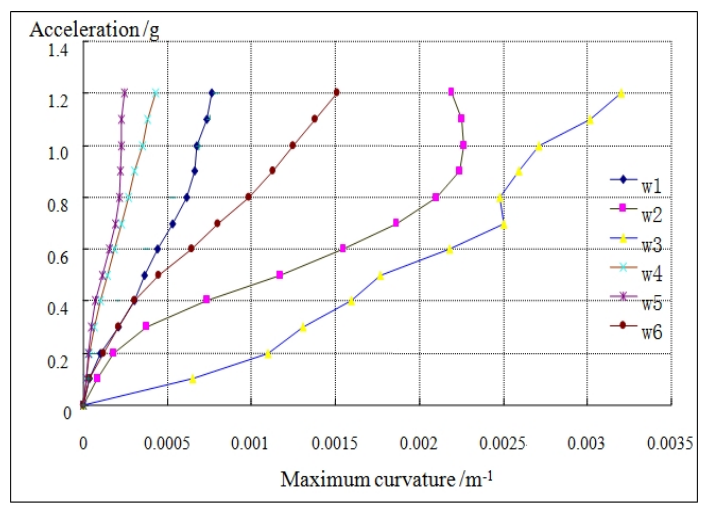

a) Longitudinal

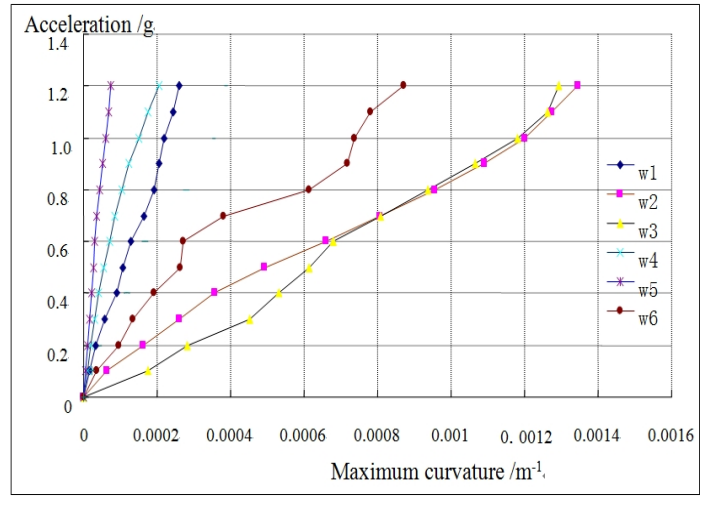

b) Transverse

Fig. 7. IDA curve

In order to analyze the damage state of the bridge pier under seismic wave, The yield area of the bridge pier will be calculated, under the action of each seismic wave, Under the action of seismic wave W3, the yield length of the bridge pier in the range of the peak acceleration of $0.1 \mathrm{~g}-1.2 \mathrm{~g}$ is discussed.

The results show that the yield region of the lateral pier is mainly concentrated in the bottom of the pier. When the peak of the local vibration reaches $0.2 \mathrm{~g}$, the lateral pier is not in the yield stage. When the peak value of the local vibration is increased to $1.2 \mathrm{~g}$, the yield of the pier bottom is close to $50 \mathrm{~m}$, which is different from that of the plastic hinge.

Under the action of longitudinal earthquake, the yield of the pier is at the top of the pier and the pier bottom,

In the calculation of the pier, the pier is the first occurrence of the yield, and then it is the top of the pier into the yield stage. Compared to the lateral pier, the yield of the pier at the bottom of the pier is smaller than that of the transverse direction, While in the pier top, the yield length is reached $20 \mathrm{~m}$.In the longitudinal direction of the bridge, although the pier is very early to yield, However, due to the existence of the anti bending point, when the peak value of the acceleration peak, The yield of the top of the pier and the top of the pier is less than the length of the transverse bridge to the bottom of the pier. 


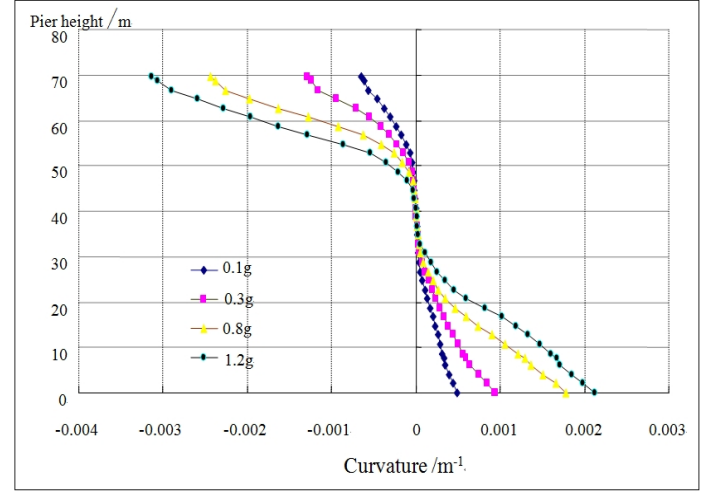

a) Transverse

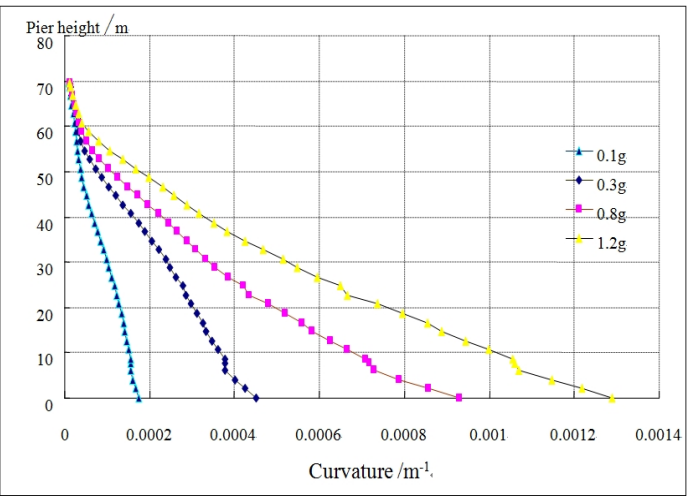

b) Longitudinal

Fig. 8 Pier curvature under seismic wave of W3

\section{Conclusions}

In this paper, the fiber model was adopted to analyze the long-span continuous rigid frame bridge. We studied the seismic characteristics, and the seismic performance evaluation using pushover and IDA methods. The conclusions are drawn as follows.

1) The influence of high vibration modals should be considered for the long-span continuous rigid frame bridge with high piers in transversely, but the influence of high vibration modals is not very obvious in longitudinally. Under the three kinds of lateral load distribution mode, the curvature variation is similar, And ultimate curvature is basically the same;

2) Through IDA analysis, the characteristics of the nonlinear seismic response of continuous rigid frame bridges are further revealed. The results show that the Pushover analysis has great limitations and cannot reflect the seismic internal force of the piers. By analyzing the distribution characteristics of bridge in IDA, it is found that the distribution of high pier horizontal seismic force is required by the bending moment.

\section{References}

[1]. JTG/TB02-01-2008 Guidelines for Seismic Design of Highway Bridges [S].

[2] Une H, Kawashima K, Shoji G. Pushover analysis of a frame bridge[J]. Journal of Structural Engineering, 1999, 45A:947 956..

[3] LIANG Zhiyao. Seismic design theory research of irregular girder bridge. Shanghai: Tongji University, 2005.

[4] LI Jianzhong, SONG Xiaodong, FAN Lichu. Investigation for displacement ductility capacity of tall piers [J].Journal of Earthquake Engineering and Engineering vibration, 2005,25(1):40-48.

[5] WANG Mengfu, CAO Xiujuan, SUN Wenlin. Incremental dynamic analysis applied to seismic risk assessment of hybrid structure [J]. Earthquake Resistant and Retrofitting, 2010, 32(1): 104-109.

[6] ZHENG Yi, Tsutomu U, GE Han-bin Ge. Seismic response predictions of multi-span steel bridges through pushover analysis[J]. Earthquake Engineering and Structural Dynamics, 2003, 32: 12591274.

[7]Helmut K. Pros and Cons of a push-over analysis of seismic performance evaluation[J]. Engineering Structures, 1998, 20:452 464.

[8] FEMA. NEHRP Guideline for seismic rehabilitation of buildings. Report No.FEMA-273, SAC Joint Venture, Federal Emergency Management Agency, Washington. DC, 1997.

[9] Quantification of building seismic performance factors ,ATC-63 project Report(90\% 
Draft),FEMA P695/April 2008,115-128 